\title{
Communication
}

\section{Survival Rate and Deformation of External Hexagon Implants with One-Piece Zirconia Crowns}

\author{
Marco Antonio Bottino ${ }^{1, *}$, Flávio Rosa de Oliveira ${ }^{1}$, Clarice Ferreira Sabino ${ }^{1}\left(0\right.$, José Cícero Dinato ${ }^{1}$, \\ Laís Regiane Silva-Concílio ${ }^{2}$ and João Paulo Mendes Tribst ${ }^{2}$ (I)
}

1 Institute of Science and Technology, São Paulo State University (Unesp), São José dos Campos, São Paulo 12220690, Brazil; flavio.oliveira@effdental.com.br (F.R.d.O.); clarice.sabino@unesp.br (C.F.S.); cicero@dinato.com.br (J.C.D.)

2 Department of Dentistry, University of Taubaté (UNITAU), Taubaté 12020-270, Brazil; regiane1@yahoo.com (L.R.S.-C.); joao.tribst@gmail.com (J.P.M.T.)

* Correspondence: marco.bottino@unesp.br

Citation: Bottino, M.A.; de Oliveira, F.R.; Sabino, C.F.; Dinato, J.C.; Silva-Concílio, L.R.; Tribst, J.P.M. Survival Rate and Deformation of External Hexagon Implants with One-Piece Zirconia Crowns. Metals 2021, 11, 1068. https://doi.org/ $10.3390 /$ met11071068

Academic Editor: Tomasz Czujko

Received: 24 May 2021

Accepted: 30 June 2021

Published: 2 July 2021

Publisher's Note: MDPI stays neutral with regard to jurisdictional claims in published maps and institutional affiliations.

Copyright: (c) 2021 by the authors. Licensee MDPI, Basel, Switzerland. This article is an open access article distributed under the terms and conditions of the Creative Commons Attribution (CC BY) license (https:/ / creativecommons.org/licenses/by/ $4.0 /)$.

\begin{abstract}
This study aimed to evaluate the survival rates of several external hexagon implants directly connected to zirconia crowns after thermomechanical fatigue. The deformation of the hexagons and the integrity of zirconia crowns were also evaluated. A monolithic zirconia crown (Y-TZP) and four different external hexagon dental implants $(n=10, N=40)$ were mounted together and embedded in polyurethane. The specimens were subjected to thermomechanical cycling for $2.5 \times 10^{6}$ cycles, at $3.0 \mathrm{~Hz}$ frequency, at $200 \mathrm{~N}$ loading. The interface of the implant/zirconia crown system, zirconia crowns integrity before and after cycling, and the implant hexagon surface were evaluated under stereomicroscopy and SEM. A nanohardness analysis was performed to verify the hardness of zirconia and implants. Statistical analysis was performed using the Kaplan-Meier test, Multi-Sample Survival Tests, Logrank Test, $(p=0.05)$. The data did not show significant differences in the survival rates of different implant groups. However, some crowns presented fractures $(16.67 \%)$ and the external hexagon region of the implants presented plastic deformations (100\%). During chewing simulation, the interface between titanium implant and zirconia abutment can promote plastic deformation in the metal and surface defects in the ceramic. In addition, the types of interface defects can be affected by the external hexagon design.
\end{abstract}

Keywords: dental implants; dental materials; zirconia; dental ceramics; biomechanics

\section{Introduction}

The success of dental implants can be evaluated by the aesthetic and mechanical conditions. For excellent osseointegration (macro and microstructurally), shape and implant type, abutment-implant connection, gaps, thread design and surface characteristics are factors that play an important role [1,2]. The wide variety of products and the choice for restorative materials can make this list even more complex to dentists.

Another important factor is the rehabilitation with implant-supported restorations. For the prosthesis manufacturing, several types of abutments can be used providing different characteristics for the peri-implant tissue and mechanical response. Metallic abutments made of titanium alloy have been proven to be a durable treatment option and are considered the "gold standard" [3]. But, to fulfill aesthetic requirements, aesthetic abutments were developed with high strength polycrystalline ceramics, such as alumina and zirconia [4-7].

Zirconia is considered a promising material because of its strength, excellent mechanical properties and biocompatibility, resulting in strong implant abutments [8-10]. Zirconia abutments of various implant-abutment geometries are available for the different types of implants, such as external hexagon, internal hexagon and even conical connections, and 
either as one-piece (zirconia one-piece abutment) or two-piece (zirconia abutment and crown) systems [11].

The forces acting on the excursion contacts and obliquely to the implant central axis may affect the misfit between abutment/implant interface. These forces on implant prostheses cannot be avoided but can be well tolerated by selecting the correct prosthetic component. Therefore, it is suggested that the use of zirconia abutments in titanium implants can cause permanent changes and deformations of the implant hexagon [12]. This is because the action of cyclic forces is able to generate fatigue in these dental materials. During fatigue cycle, dental implants can develop internal micro cracks that increase in number and size with time. For the abutment/implant interface the fatigue cycle can lead to micro-movements resulting in abutment loosening, wear, cracks in the implant, cracks in the screw or even fracture of the dental implant $[13,14]$. In addition, the incidence of masticatory loads in this type of treatment can lead to fractures of the ceramic material and other components of the prosthesis [15].

The objective of the current study was to evaluate the influence of thermomechanical cycling on the fatigue strength of the zirconia crowns and the effects on the external hexagon of the implants under simulated oral conditions with temperature variations, moisture, compressive cyclic loading and sliding contact.

\section{Materials and Methods}

Thirty-six monolithic zirconia crowns were manufactured and screw-retained to different external hexagon implants.

Polyurethane cylinders were made (F16, Axson, Socorro, São Paulo, Brazil). The base and the catalyst of the polyurethane resin were mixed in equal portions and poured inside $3 / 4$ inch in diameter PVC cylinders ( $2 \mathrm{~cm}$ in height). After the polymerization reaction, ISO 14801 was followed $[14,16]$. The milling of the polyurethane block for implant fixation was performed using the specific and sequential milling burs, with the aid of a precision dental milling machine (BioArt Dental Equipment, São Carlos, Brazil), in order to determine a same axis for implant placement for all samples. In this study, the implants from four different manufacturers were used (Bonelike Hexagonal External $\varnothing 4.0 \times 11.5 \mathrm{~mm}$ [G1]; Titamax HE Smart Cortical $\varnothing 3.75 \times 13.0 \mathrm{~mm}$ [G2]; Brånemark System MK III Ø $3.75 \times 11.5$ mm [G3]; Cortical Screw Master Easy-Grip Porous RD $\varnothing 3.75 \times 11.5 \mathrm{~mm}$ [G4]), all of them with $4.1 \mathrm{~mm}$ of prosthetic platform. Then the implants were screw-retained into the center of the polyurethane cylinders. The implant platform was previously marked with a pen to standardize its position $3 \mathrm{~mm}$ below the surface of the resin cylinder (Table 1 ).

Table 1. Materials used in the study ${ }^{1}$.

\begin{tabular}{|c|c|c|}
\hline Material & Commercial Name & Manufacturer \\
\hline Polyurethane resin & F160 & $\begin{array}{l}\text { Axson Brasil HighTech } \\
\text { (Socorro, SP, Brazil) }\end{array}$ \\
\hline Grade 4 Titanium & Bonelike & $\begin{array}{c}\text { Biotechnology } 3 \mathrm{i} \\
\text { (Rio Claro, SP, Brazil) }\end{array}$ \\
\hline Grade 4 Titanium & Master & $\begin{array}{c}\text { Conexão Sistemas de Prótese } \\
\text { (Arujá, SP, Brazil) }\end{array}$ \\
\hline Grade 4 Titanium & Titamax Smart & $\begin{array}{c}\text { Neodent } \\
\text { (Curitiba, PR, Brazil) }\end{array}$ \\
\hline Grade 4 Titanium & Branemark System MK III RP & $\begin{array}{c}\text { Nobel Biocare } \\
\text { (Gotenborg, Sweden) }\end{array}$ \\
\hline 3-YTZP & Prettau Zirkon & $\begin{array}{l}\text { Zirkonzahn GmbH } \\
\text { (Gais, Italy) }\end{array}$ \\
\hline
\end{tabular}

${ }^{1}$ According to the manufacturers' information.

The crown design was the same for all groups, but to assure a perfect fit in each type of implant design, the database in the CAD (computer aided design) software was used 
(600 Zirkonzahn 600 art, Neuler, Germany) and the crowns were virtually customized at the connection. The crowns were then milled (Zirkonzahn M5, Neuler, Germany) in zirconia $25 \%$ larger in size, and sintered in a ceramic oven (Zirkonnofen 600, Zirkonzahn, Neuler, Germany) for a sintering period of $10 \mathrm{~h}$ (air medium), according to the following schedule: temperature elevation $8{ }^{\circ} \mathrm{C} / \mathrm{min}$; holding time $2 \mathrm{~h}$ and final temperature, $1600{ }^{\circ} \mathrm{C}$. The crowns were retained directly on to the implant platform with a torque of $30 \mathrm{~N} / \mathrm{cm}$, which was measured with a digital torque wrench (Mitutoyu, Kawasaki City, Japan).

In a sliding fatigue machine (BioPdi Sliding, BioPdi, São Carlos, Brazil), the specimens were positioned in a fixed metal base, with distilled water at $37^{\circ} \mathrm{C}$ at a $90^{\circ}$ angle between the occlusal surface and the stainless-steel tip with $3.18 \mathrm{~mm}$ in diameter. The tip of the load applicator contacted the uppermost part of the zirconia component where it performed the first touch with an axial load of $50 \mathrm{~N}$ at 1.0 bar of pressure and slid over it with $2.0 \mathrm{~mm}$ of extension. $2.5 \times 10^{6}$ cycles were performed at $3 \mathrm{~Hz}$ frequency. Every 500,000 cycles the test was interrupted, the specimens inspected in a stereomicroscope for failures (Stereo Discovery.V12, Carl Zeiss, LLC, Thornwood, NY, USA), and suspended from testing in the presence of fractures. The following failures modes were considered: fracture of the screw, fracture of the crown, complete loosening of the crown and fracture of the implant. If no failure was observed, the specimens continued to undergo sliding fatigue until they failed or until the end of the test.

The zirconia crowns were analyzed under an optical microscope and through SEM (Scanning electron microscopy) to observe the initial topography and possible damage (deformation) caused to the implant during fatigue. The zirconia crown was then gold sputtered for SEM, receiving $12 \mathrm{~nm}$ of gold layer (Emitech SC7620 Sputter Coater). The analysis of the fractured crowns was carried out to determine critical defects and direction of crack propagation.

A nanohardness test (Berkovich tip) for implants and zirconia crowns were performed to verify the Knoop hardness of the evaluated materials. (Nano-Inducer NHT ${ }^{2}$, Anton Paar, Austria). The maximum load used for implants and zirconia crowns were $50 \mathrm{~g}$, with an initial loading rate of $10 \mathrm{~g} / \mathrm{min}$, with a time of $30 \mathrm{~s}$ to reach the maximum load used, the tip stood still for $10 \mathrm{~s}$ and then started the unloading rate of $10 \mathrm{~g} / \mathrm{min}$, equivalent to $30 \mathrm{~s}$.

Statistical analysis was performed using the Kaplan-Meier test and Multi-Sample Survival Test (Log-rank Test) $(p=0.05)$.

\section{Results}

All implants presented plastic deformations on the hexagon region (Figure 1). One implant type-Bonelike hexagon external Ø $4.0 \times 11.5 \mathrm{~mm}$ Biotechnology/Biomet 3i from Brazil- showed a cervical fracture (near the prosthetic connection), which was also observed in SEM (Scanning Electron Microscopy, Inspect S50, FEI, Brno, Czech Republic).

The topography of the initial crown presented imperfections at a microscopic level that may have triggered fractures during fatigue. The fractured crowns subjected to the fatigue test demonstrated that the fractures were originated at the regions where the vertices of the hexagon of the implant were coupled (Figure 1).

The evaluation of the interface between the implants and crowns in a stereomicroscope $(40 \times)$, did not show failure in the cervical connection. Each set was analyzed at four different positions, rotating $90^{\circ}$, from an initial marking and so on (Figure 2). 
A)

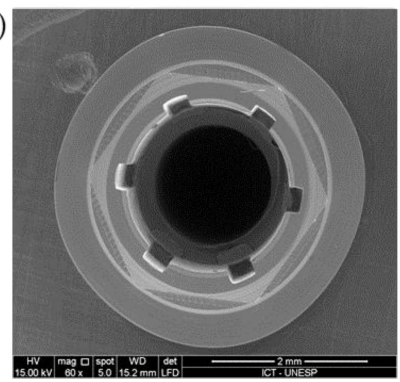

E)

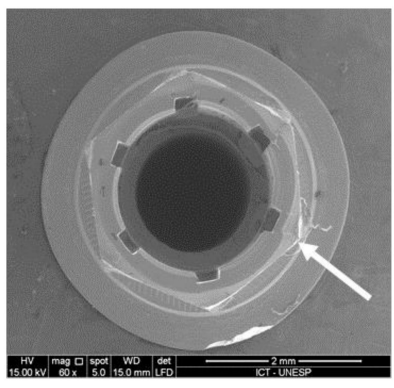

B)

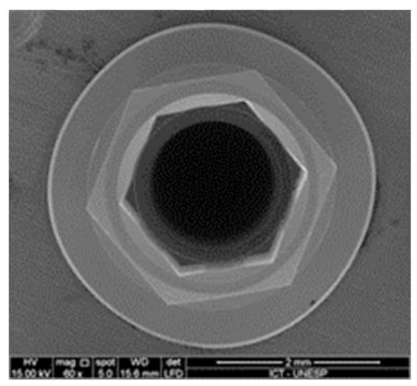

F)

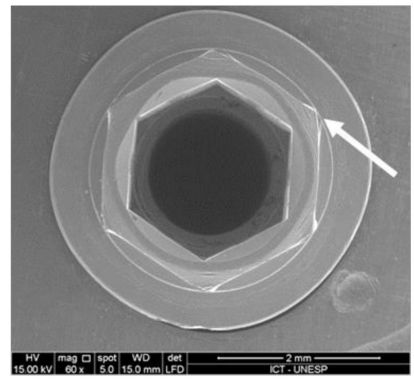

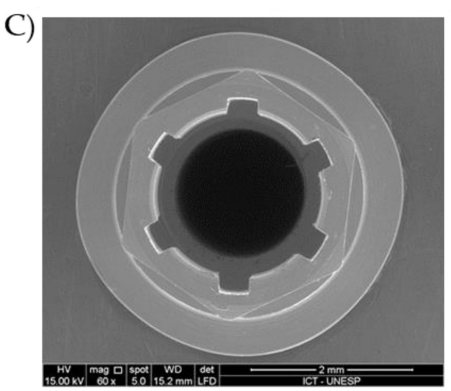

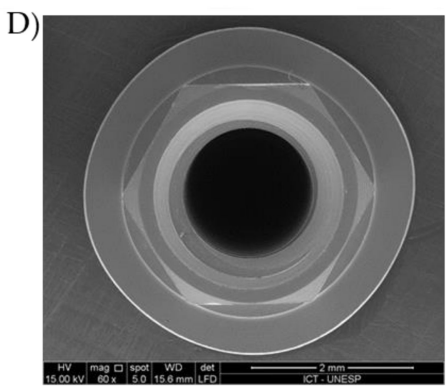

G)
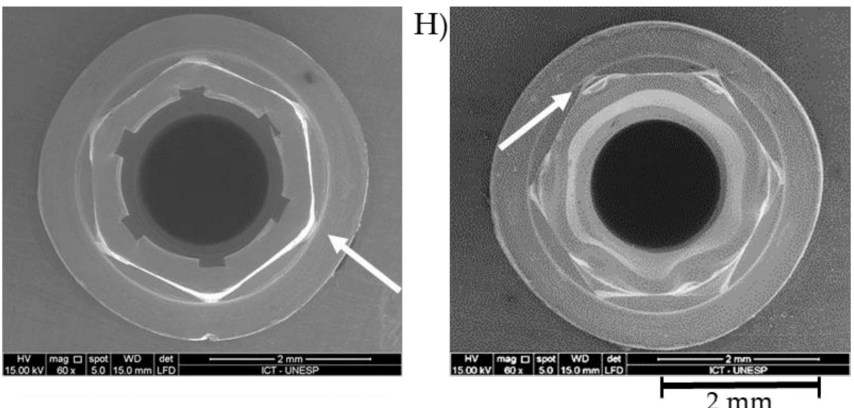

Figure 1. Initial (A-D) and final conditions (E-H) of representative implants subjected to the fatigue testing. The arrows point out the plastic deformations of the hexagons.
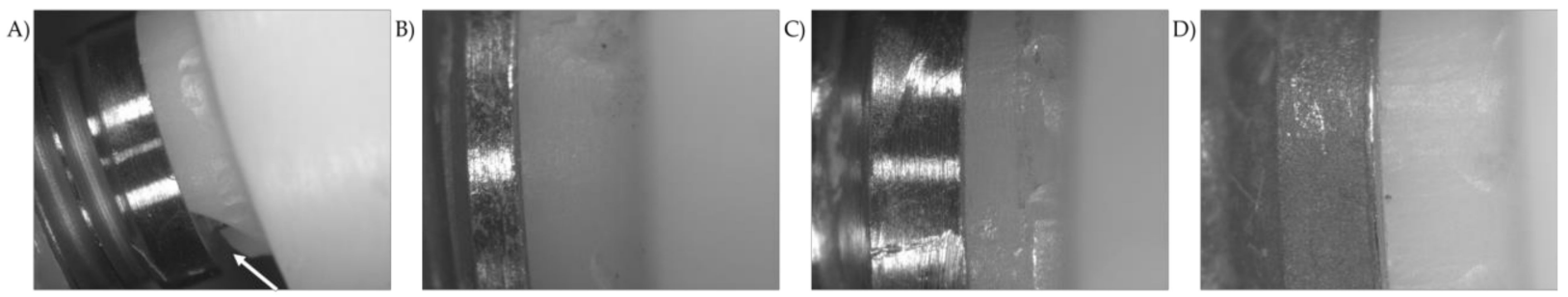

Figure 2. Marginal assessment after $2.5 \times 10^{6}$ cycles $(40 \times)$ of the interface between implants and zirconia crowns. Arrow: zirconia fracture G1 (A), G2 (B), G3 (C) and G4 (D).

Only partial fractures in the cervical region of the zirconia crowns, close to the implant hexagons, occurred. There were no complete fractures. Six zirconia crowns fractured at the cervical margin (Figure 3). Only one screw loosening was observed (between zero and 500,000 cycles).

The results of hardness of the materials are shown in (Table 2). No differences in hardness existed between the implant types, but the zirconia crowns were harder than titanium.

Table 2. Nanohardness ${ }^{1}$ of zirconia and implants used in the study. Same lower case letter means no statistically significant differences between the implant types.

\begin{tabular}{ccc}
\hline Material & Average & Standard Deviation \\
\hline Zirconia Crown & 1645.53 & 71.77 \\
G1 & $325.12^{\mathrm{a}}$ & 20.60 \\
G2 & $390.80^{\mathrm{a}}$ & 41.25 \\
G3 & $373.75^{\mathrm{a}}$ & 25.65 \\
G4 & $368.41^{\mathrm{a}}$ & 24.44 \\
\hline
\end{tabular}

${ }^{1}$ According to method: Oliver and Pharr. HVIT, Vickers. 

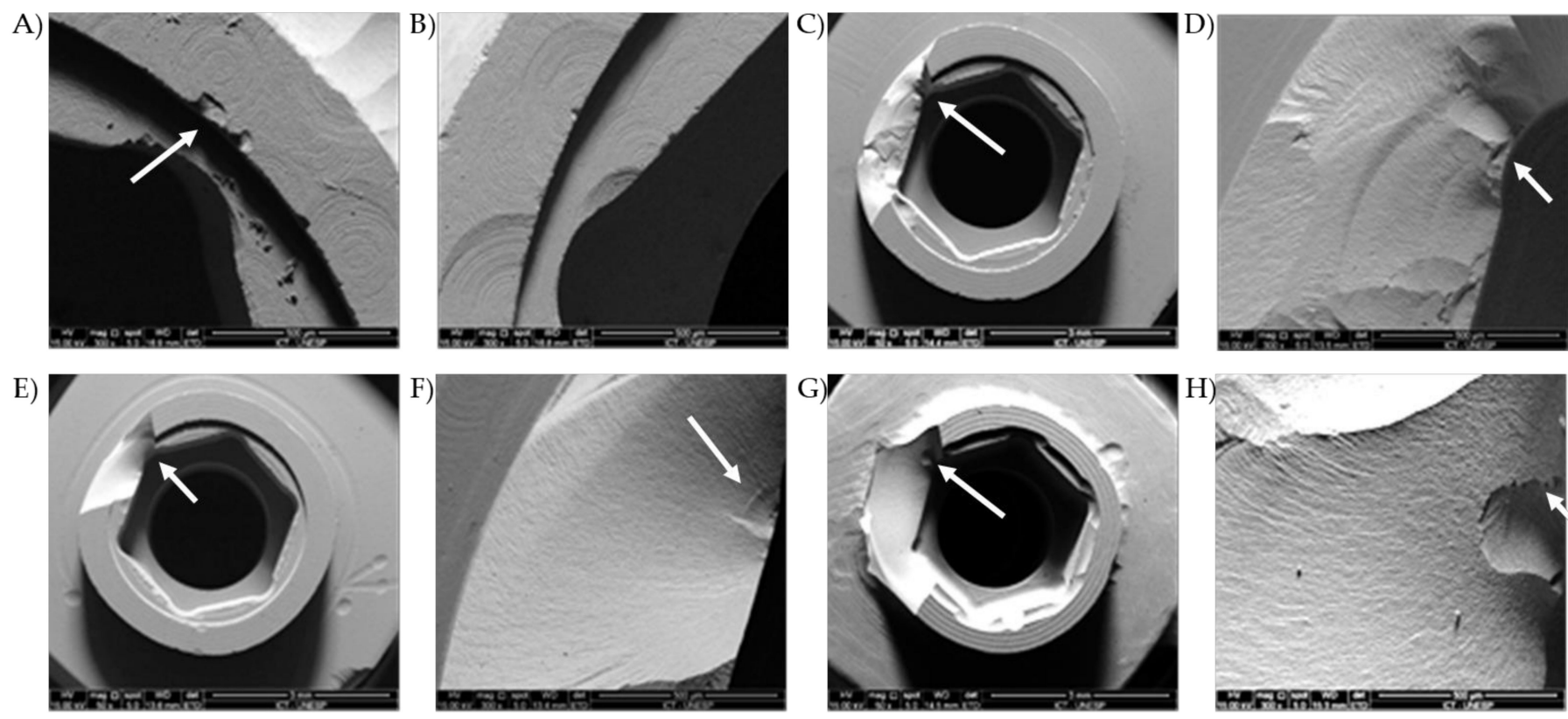

I)
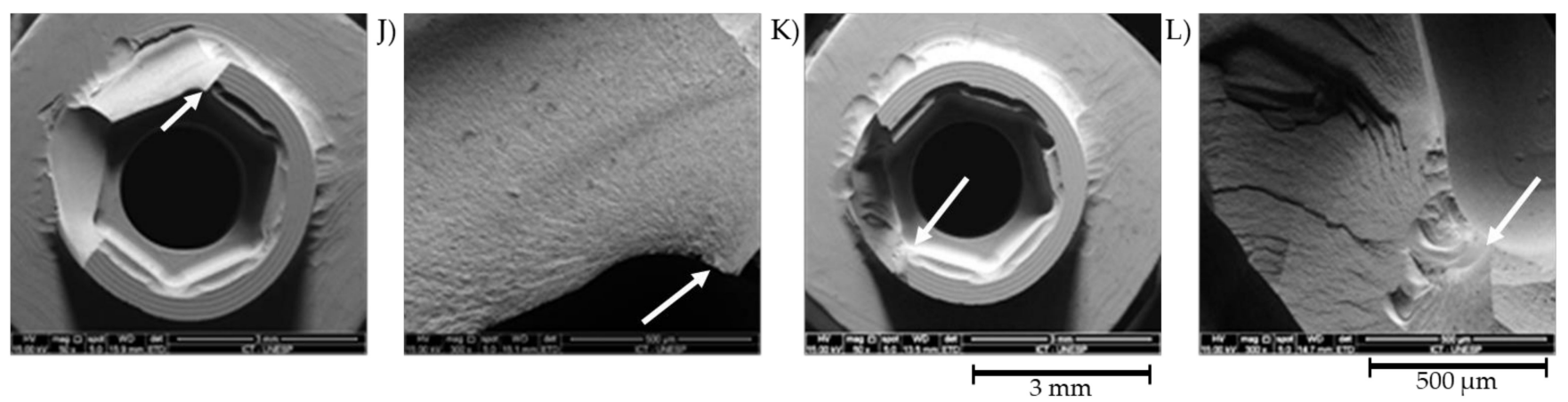

Figure 3. Small defects from milling are seen in the internal parts of the representative crowns (A-L). The fractured crowns are seen on the left and the circles are the depicted images on the right. The defects close to the hexagons (solid arrows) and fracture marks were mainly hackles and arrest lines.

The survival rates depended on the implant configuration: G2 showed 100\% of survival rate during the chewing simulation. In spite of that, the $p$ values for all cycling intervals were greater than 0.05 (Log-rank Test), with no significant (Figure 4) differences in the survival of crowns of the four groups of implants with regard to the thermomechanical cycling (Table 3). The scores for the level of plastic deformation for each implant are summarized in Figure 5.

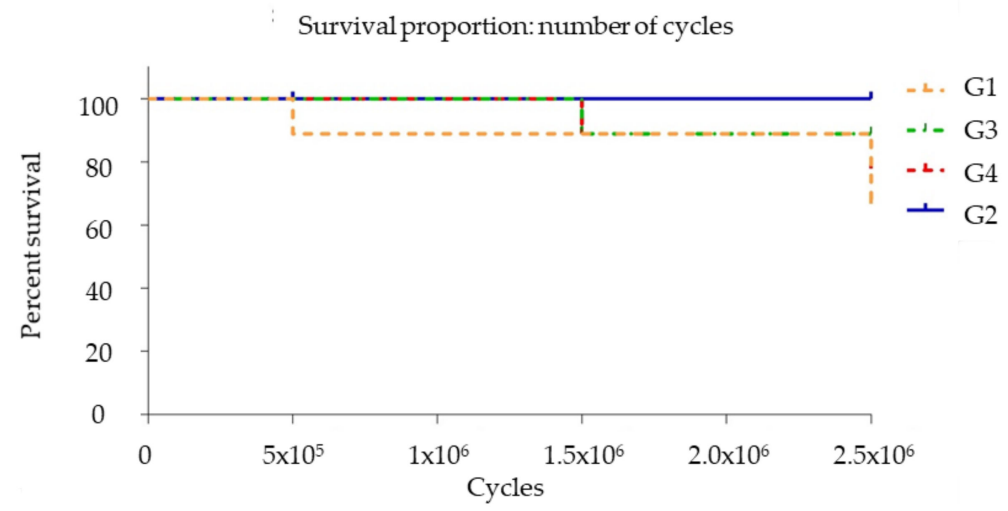

Figure 4. The Kaplan-Meier estimate curve for survival of zirconia crowns of four types of implants. 
Table 3. Overall Comparisons ${ }^{1}$ in time variable (cycles) according to the event variable (implant type).

\begin{tabular}{cccc}
\hline & \multicolumn{3}{c}{ Log-Rank Test } \\
\hline Implant & $n$ & Sum & Mean \\
\hline G1 & 9 & 1.5294 & 0.1699 \\
G2 & 9 & 0.4706 & 0.0523 \\
G3 & 9 & -1.4706 & -0.1634 \\
G4 & 9 & -0.5294 & -0.0588 \\
Chi-Square & 3.45 & 3.49 & 3.29 \\
DF & 3 & 3 & 3 \\
$p$ & 0.3275 & 0.3219 & 0.3487 \\
\hline
\end{tabular}

${ }^{1}$ Multi-Sample Survival Tests

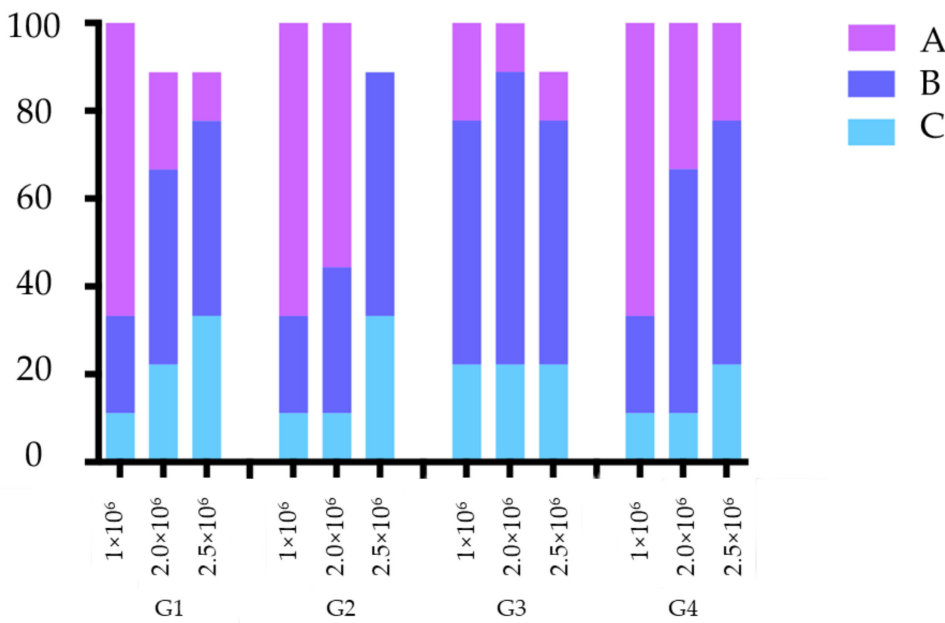

Figure 5. Scores for the level of plastic deformation and their percentages according to the number of cycles and implant types. Score A (no visible mark or plastic deformation), score B (slight Plastic deformation at one edge of the external hexagon), Score $\mathbf{C}$ (plastic deformation at all edges of the external hexagon).

\section{Discussion}

This study followed ISO 14801 standard for the assembling of the implants and connections. As observed in the present study and others that used the same test setup $[17,18]$ one-piece zirconia abutments have a tendency for lower stability and fracture during fatigue cycling. Therefore, the present study demonstrated that depending on the hexagonal platform configuration earlier failures are possible. The former two implant types present internal grooves, whereas the third one present internal vertices, and all of these features serve for implant fixation during the surgical step. The G2 implant, was the only group that did not present zirconia failures, has no features in the internal region and this possibly played a role in crowns survival.

The literature reports that zirconia as biomaterial in oral rehabilitations can present an acceptable mechanical response even in full-arch implant-supported total prosthesis [19], and for screw-retained restorations the use of resin composite should be used to seal the screw access hole [20]. However, the present study suggests that for unitary restorations, the mechanical problems can occur at the cervical level, near the emergence profile at the implant platform. Cervical fractures of the zirconia crowns were observed from the 500,000 cycles until the $2.5 \times 10^{5}$ cycle. On the one hand, the inner cervical region of the zirconia crown in contact with the implant hexagon under loading, generated stresses, favoring the fracture on this region. The immersion in water at $37^{\circ} \mathrm{C}$ certainly facilitated the development of cracks [21] as the combination of mechanical stress and moisture exposure critically increase ceramic temperature degradation [22]. This phenomenon of aging initiates a spontaneous transformation of the phase of zirconia crystals from the tetragonal phase to the monoclinic phase, weakening the material. 
On the other hand, micromotion during fatigue was able to round the implant hexagon [12], which in turn led to poor fit of the abutment and facilitated fracture. In terms of implant deformation, there was also an overall rounding of the hexagons due to the difference in hardness of zirconia compared to that of titanium. G3 and G4 implants showed higher plastic deformation than those from G1 and G2, as a result of their intricate design that led to increased micromovement of the crown.

All platforms of the external hexagon implants were evaluated by one operator with a stereomicroscope and in SEM. The adaptation of the implant platforms with the abutments was evaluated and did not show significant gaps (Figure 2). This agrees with previous findings in which the marginal fit of zirconia crowns retained directly on implants was better than the fit on a titanium base [23]. The opposite was true for the results of strength, probably due to less horizontal movement when cemented on titanium bases.

The variety of implant-abutment connections and the discrepancies in the wall thickness of the abutment can therefore influence the performance of the zirconia abutments [24]. A minimum thickness of abutment walls should exist to achieve suitable fracture strength [25]. We used robust one-piece zirconia crowns (Ø: $4.16 \pm 0.04 \mathrm{~mm}$ ); but the presence of previous machining damage, along with the stresses due to a $30^{\circ}$ inclination of the implant and crown assembly in relation to the load applicator, triggered the initiation of failures in the cervical regions of the crowns. Although the fractures were not complete, six crowns showed fractures in the cervical region. Previous investigations have already reported that the cervical region is the most prone to failure region in implant-supported ceramic restorations corroborating the results of the present study.

This research used a sliding fatigue scheme $(2.0 \mathrm{~mm})$ with a force of $50 \mathrm{~N}$, simulating the physiological oral conditions suggesting that, at a greater number of cycles, the number of fractured crowns could increase. In addition, the magnitude of occlusal loads is important for implant longevity and loads above the physiological, such as those of bruxism and teeth clenching, can increase implant/prosthesis stress, causing earlier mechanical complications [26]. All of these should be taken into consideration when performing a monolithic zirconia crown made directly on implants. However, it is important to consider that the biomechanical response can be modified if a fixed dental prosthesis is considered with more implants fixtures to support the framework and dissipate the chewing load [27].

The hardness of the zirconia crowns added to the effect of the sliding fatigue, and the lower hardness value of all the implants, were probably responsible for the plastic deformation in the region of the implant hexagons. The design of the external cervical hexagon of the implant may also have had an influence on deformation of such implants and fracture of zirconia crowns. To avoid the mechanical problems reported in the present study, the use of titanium base in hybrid abutments could be an alternative treatment that will keep the interface between implant and abutment only with metallic surfaces [28,29].

\section{Conclusions}

During chewing simulation and fatigue cycling, the zirconia/titanium interface between implant and abutment can promote plastic deformation in the metal and surface defects in the ceramic. In addition, the types of interface defects can be affected by the external hexagon design.

Author Contributions: Conceptualization, M.A.B., F.R.d.O. and J.P.M.T.; methodology, M.A.B. and C.F.S.; software, J.C.D., L.R.S.-C. and J.P.M.T.; validation, M.A.B. and J.P.M.T.; formal analysis, M.A.B., C.F.S., L.R.S.-C. and J.P.M.T.; investigation, M.A.B., F.R.d.O. and J.C.D.; resources, M.A.B., F.R.d.O., J.C.D. and J.P.M.T.; data curation, M.A.B., L.R.S.-C. and J.P.M.T.; writing-original draft preparation, M.A.B., F.R.d.O. and J.C.D.; writing-review and editing, C.F.S., L.R.S.-C. and J.P.M.T.; visualization, M.A.B. and J.P.M.T.; supervision, M.A.B.; project administration, M.A.B.; funding acquisition, M.A.B. and J.P.M.T. All authors have read and agreed to the published version of the manuscript.

Funding: This research received no external funding.

Institutional Review Board Statement: Not applicable. 
Informed Consent Statement: Not applicable.

Data Availability Statement: Data available on request.

Acknowledgments: The authors thank EFF- Dental for the materials support. The authors also thank Alexandre Abdalla Alonso for the assistance during the samples preparation and in vitro testing.

Conflicts of Interest: The authors declare no conflict of interest.

\section{References}

1. Abuhussein, H.; Pagni, G.; Rebaudi, A.; Wang, H.-L. The effect of thread pattern upon implant osseointegration. Clin. Oral Implants Res. 2010, 21, 129-136. [CrossRef]

2. Jalalian, E.; Yousofi, Z. Comparing torque loss in standard implants and short implants with increased vertical cantilever abutments: An in vitro study. Braz. Dent. Sci. 2020, 24, 1-8.

3. Pjetursson, B.E.; Sailer, I.; Zwahlen, M.; Hämmerle, C.H.F. A systematic review of the survival and complication rates of allceramic and metal-ceramic reconstructions after an observation period of at least 3 years. Part I: Single crowns. Clin. Oral Implants Res. 2007, 18 (Suppl. 3), 73-85. [CrossRef] [PubMed]

4. Fonseca, M.; Molinero-Mourelle, P.; Forrer, F.A.; Schnider, N.; Paul Hicklin, S.; Schimmel, M.; Brägger, U. Clinical performance of implant crowns with customized zirconia abutments. A prospective cohort study with a 4.5- to 8.8-year follow-up. Clin. Oral Implants Res 2021. [CrossRef]

5. Mühlemann, S.; Truninger, T.C.; Stawarczyk, B.; Hämmerle, C.H.F.; Sailer, I. Bending moments of zirconia and titanium implant abutments supporting all-ceramic crowns after aging. Clin. Oral Implants Res. 2014, 25, 74-81. [CrossRef]

6. Bottino, M.A.; Rocha, R.F.V.; Anami, L.C.; Özcan, M.; Marques de Melo, R. Fracture of Zirconia abutment with metallic insertion on anterior single titanium implant with internal hexagon: Retrieval analysis of a failure. Eur. J. Prosthodont. Restor. Dent. 2016, 24, 164-168. [PubMed]

7. Datte, C.E.; Tribst, J.P.M.; Dal Piva, A.M.O.; Nishioka, R.S.; Bottino, M.A.; Evangelhista, A.D.M.; Monteiro, F.M.M.; Borges, A.L.S. Influence of different restorative materials on the stress distribution in dental implants. J. Clin. Exp. Dent. 2018, 10, 439-444. [CrossRef]

8. Sailer, I.; Philipp, A.; Zembic, A.; Pjetursson, B.E.; Hämmerle, C.H.F.; Zwahlen, M. A systematic review of the performance of ceramic and metal implant abutments supporting fixed implant reconstructions. Clin. Oral Implants Res. 2009,20 (Suppl. 4), 4-31. [CrossRef]

9. Rauscher, O. Impression-free implant restorations with Cerec InLab. Int. J. Comput. Dent. 2011, 14, 139-146.

10. Adolfi, D.; Mendes Tribst, J.P.; Souto Borges, A.L.; Bottino, M.A. Torque maintenance capacity, vertical misfit, load to failure, and stress concentration of Zirconia restorations cemented or notched to titanium bases. Int. J. Oral Maxillofac. Implants 2020, 35, 357-365. [CrossRef]

11. Sailer, I.; Sailer, T.; Stawarczyk, B.; Jung, R.E.; Hämmerle, C.H.F. In vitro study of the influence of the type of connection on the fracture load of zirconia abutments with internal and external implant-abutment connections. Int. J. Oral Maxillofac. Implants 2009, 24, 850-858. [PubMed]

12. Gehrke, S.A.; Poncio da Silva, P.M.; Calvo Guirado, J.L.; Delgado-Ruiz, R.A.; Dedavid, B.A.; Aline Nagasawa, M.; Shibli, J.A. Mechanical behavior of zirconia and titanium abutments before and after cyclic load application. J. Prosthet. Dent. 2016, 116, 529-535. [CrossRef]

13. Hoyer, S.A.; Stanford, C.M.; Buranadham, S.; Fridrich, T.; Wagner, J.; Gratton, D. Dynamic fatigue properties of the dental implant-abutment interface: Joint opening in wide-diameter versus standard-diameter hex-type implants. J. Prosthet. Dent. 2001, 85, 599-607. [CrossRef] [PubMed]

14. Tribst, J.P.M.; Dal Piva, A.M.d.O.; da Silva-Concílio, L.R.; Ausiello, P.; Kalman, L. Influence of Implant-Abutment Contact Surfaces and Prosthetic Screw Tightening on the Stress Concentration, Fatigue Life and Microgap Formation: A Finite Element Analysis. Oral 2021, 1, 9. [CrossRef]

15. Karl, M.; Graef, F.; Wichmann, M.G.; Heckmann, S.M. The effect of load cycling on metal ceramic screw-retained implant restorations with unrestored and restored screw access holes. J. Prosthet. Dent. 2008, 99, 19-24. [CrossRef]

16. Thomé, G.; Torres Gomes, A.F.; de Moura, M.B.; Felippi, C.; Trojan, L.C. Evaluation of the mechanical reliability of different implant-abutment connections for single crowns according to the ISO 14801 fatigue test protocol. Int. J. Oral Maxillofac. Implants 2021, 36, 47-54. [CrossRef] [PubMed]

17. Truninger, T.C.; Stawarczyk, B.; Leutert, C.R.; Sailer, T.R.; Hämmerle, C.H.F.; Sailer, I. Bending moments of zirconia and titanium abutments with internal and external implant-abutment connections after aging and chewing simulation: Bending moments of zirconia and titanium abutments. Clin. Oral Implants Res. 2012, 23, 12-18. [CrossRef]

18. Sailer, I.; Asgeirsson, A.G.; Thoma, D.S.; Fehmer, V.; Aspelund, T.; Özcan, M.; Pjetursson, B.E. Fracture strength of zirconia implant abutments on narrow diameter implants with internal and external implant abutment connections: A study on the titanium resin base concept. Clin. Oral Implants Res. 2018, 29, 411-423. [CrossRef] [PubMed]

19. Tribst, J.P.M.; Dal Piva, A.M.d.O.; Borges, A.L.S.; Rodrigues, V.A.; Bottino, M.A.; Kleverlaan, C.J. Does the prosthesis weight matter? 3D finite element analysis of a fixed implant-supported prosthesis at different weights and implant numbers. J. Adv. Prosthodont. 2020, 12, 67-74. [CrossRef] 
20. Tribst, J.P.M.; Dal Piva, A.M.d.O.; Gonçalves, N.I.Ê.; Borges, A.L.S.; Bottino, M.A.; Kleverlaan, C.J. Polymerization shrinkage and push-out bond strength of different composite resins for sealing the screw-access hole on implant-supported crowns. J. Adhes. Dent. 2020, 22, 523-530. [PubMed]

21. Guazzato, M.; Albakry, M.; Ringer, S.P.; Swain, M.V. Strength, fracture toughness and microstructure of a selection of all-ceramic materials. Part II. Zirconia-based dental ceramics. Dent. Mater. 2004, 20, 449-456. [CrossRef]

22. Amaral, M.; Valandro, L.F.; Bottino, M.A.; Souza, R.O.A. Low-temperature degradation of a Y-TZP ceramic after surface treatments: Zirconia Ltd After Surface Treatments. J. Biomed. Mater. Res. B Appl. Biomater. 2013, 101, 1387-1392. [CrossRef] [PubMed]

23. Moilanen, P.; Hjerppe, J.; Lassila, L.V.J.; Närhi, T.O. Fracture strength and precision of fit of implant-retained monolithic Zirconia crowns. J. Oral Implantol. 2018, 44, 330-334. [CrossRef] [PubMed]

24. Nguyen, H.Q.; Tan, K.B.; Nicholls, J.I. Load fatigue performance of implant-ceramic abutment combinations. Int. J. Oral Maxillofac. Implants 2009, 24, 636-646. [PubMed]

25. Manicone, P.F.; Rossi Iommetti, P.; Raffaelli, L. An overview of zirconia ceramics: Basic properties and clinical applications. J. Dent. 2007, 35, 819-826. [CrossRef]

26. De Boever, A.L.; Keersmaekers, K.; Vanmaele, G.; Kerschbaum, T.; Theuniers, G.; De Boever, J.A. Prosthetic complications in fixed endosseous implant-borne reconstructions after an observations period of at least 40 months: Prosthetic Complications In Implant-Borne Fixed Reconstructions. J. Oral Rehabil. 2006, 33, 833-839. [CrossRef]

27. Silveira, M.P.M.; Campaner, L.M.; Bottino, M.A.; Nishioka, R.S.; Borges, A.L.S.; Tribst, J.P.M. Influence of the dental implant number and load direction on stress distribution in a 3-unit implant-supported fixed dental prosthesis. Dent. Med. Probl. 2021, 58, 69-74. [CrossRef]

28. Tribst, J.P.M.; Dal Piva, A.M.O.; Özcan, M.; Borges, A.L.S.; Bottino, M.A. Influence of ceramic materials on biomechanical behavior of implant supported fixed prosthesis with hybrid abutment. Eur. J. Prosthodont. Restor. Dent. 2019, 27, 76-82. [PubMed]

29. Matos, J.D.; Arcila, L.V.; Ortiz, L.P.; Lopes, G.R.; Anami, L.C.; Ramos, N.C.; Saavedra, G.S.; Tribst, J.P.; Bottino, M.A. Hybrid abutment during prosthetic planning and oral rehabilitation. Minerva Dent. Oral Sci. 2021. [CrossRef] 